\title{
A comparison of lower canine retraction and loss of anchorage between conventional and self-ligating brackets: a single-center randomized split-mouth controlled trial
}

\author{
André da Costa Monini ${ }^{1,2}$ • Luiz Gonzaga Gandini Júnior ${ }^{3,4,5,6}$. \\ Alexandre Protásio Vianna ${ }^{1,2} \cdot$ Renato Parsekian Martins ${ }^{2,3}$
}

Received: 22 December 2015 / Accepted: 11 May 2016/Published online: 31 May 2016

(C) Springer-Verlag Berlin Heidelberg 2016

\begin{abstract}
Objective To evaluate the rate of lower canine retraction, anchorage loss, and changes on lower canines and first molars axial inclination using self-ligating and conventional brackets. Materials and methods Twenty-five adult patients with a treatment plan involving extractions of four first premolars were selected for this split-mouth trial and had either conventional or self-ligating brackets bonded to lower canines in a block randomization. Retraction was accomplished using 100-g nickel titanium closed-coil springs, which were reactivated each 4 weeks. Oblique radiographs were taken before and after total canine retraction and the cephalograms were superimposed on stable structures of the mandible. Cephalometric points were digitized twice by a singleblinded operator for error control and the average of the points were used to determine the following variables: canine cusp horizontal changes, molar cusp horizontal changes, and
\end{abstract}

Electronic supplementary material The online version of this article (doi:10.1007/s00784-016-1855-7) contains supplementary material, which is available to authorized users.

Luiz Gonzaga Gandini Júnior luizgandini@uol.com.br

1 Student of Faculdade de Odontologia de Araraquara, Universidade Estadual Paulista, UNESP, Araraquara, São Paulo, Brazil

2 Rua Humaita, 1680 (Centro), 14801-385 Araraquara, São Paulo, Brazil

3 Faculdade de Odontologia de Araraquara, Universidade Estadual Paulista, UNESP, Araraquara, São Paulo, Brazil

4 Baylor College of Dentistry, Dallas, TX, USA

5 USA and Saint Louis University, Saint Louis, MO, USA

6 Av. Casemiro Perez, 560, Vila Harmonia, Araraquara, São Paulo CEP 14802-600, Brazil angulation changes in canines and molars. Paired $t$ tests were used to analyze the blinded data for group differences.

Results All patients reached final phase without bracket debonds. No differences were found between the two groups for all variables tested. No serious harm was observed.

Conclusion Both brackets showed the same rate of canine retraction and loss of anteroposterior anchorage of the molars. No changes were found between brackets regarding the inclination of canines and first molars.

Clinical Relevance Using self-ligating brackets to retract lower canines will not increase the velocity of tooth movement, does not increase anchorage, and does not decrease tipping.

Keywords Canine retraction $\cdot$ Anchorage $\cdot$ Self-ligating brackets · Tooth movement rate

\section{Introduction}

The main advantage attributed to self-ligating bracket (SLBs) is the lower levels of friction produced when they are compared to conventional brackets (CBs) [1-6]. Since friction is one of the factors that supposedly influences movement rates and anchorage, it is logical to assume that SLBs would allow faster space closure than CBs would. Controversially, recent systematic reviews have failed to report so, when canine movement rates were accessed [7, 8], challenging what logically would make sense. Even though several randomized clinical trials have been conducted comparing those two kinds of brackets [7-17], it has been suggested [18] that more clinical trials are needed to assess tooth movement rates during space closure when SLB and CB are compared.

The assessment of canine retraction rates is probably the best method to investigate if SLBs are reliable in improving sliding mechanisms when compared to $\mathrm{CB}$. Even though 
Table 1 Sample characteristics

\begin{tabular}{llll}
\hline Mean age in T1 (years) & $23.32 \pm 5.08$ & & \\
Age range (years) & $17.66-35.49$ & & \\
Gender & Females & Males & Total \\
& 16 & 09 & 25 \\
\hline
\end{tabular}

some reports have ruled out the superiority of one bracket type over another when the retraction of maxillary canines are compared $[12,14,19]$, it could be argued that the rates for mandibular canines might be different if they tend to rotate more than the upper canines do due to different positions of their axes of resistance. Up to this point, only one report [14] compared SLB and CB, and the results suggest that there is no effect of bracket type while retracting lower canines. That report, however, has studied the retraction for only 8 weeks and it could be argued that a longer time of follow up might show different results.

Another attributed advantage to SLB is a smaller loss of anchorage of the posterior dentition when retraction occurs. This is based on the application of lower forces for retraction, which would produce suboptimal stresses to the posterior dentition, keeping those teeth from moving effectively as the anterior teeth are retracted. Even though some articles have failed to corroborate that hypothesis on the maxillary arch $[20,21]$, it is unknown if the mandibular dentition would respond likewise since this hypothesis has not been tested in the orthodontic literature so far.
The aims of this research was to assess differences on lower canine movement rates, anchorage loss of lower molars, and changes of inclinations of those teeth using SLB and CB.

\section{Materials and methods}

The software PS: Power and Sample Size Calculation, version 3.0 was used to determine the sample size a priori [22]. Based on an estimated difference between groups of $0.35 \mathrm{~mm} / \mathrm{month}$ for lower canine retraction rates and a standard deviation of $0.6 \mathrm{~mm}$, taken from a previous study [14], a sample size of 25 patients/group was chosen (for an $\alpha$ of 0.05 and a power of $80 \%)$.

Twenty-five class I biprotrusive adult patients requiring four first premolar extractions, with arch length discrepancy below $4 \mathrm{~mm}$, were selected out of 52 patients who sought treatment at our university (Table 1). Three patients did not attend the initial screening and 24 were excluded due to tooth loss or arch length discrepancy above $4 \mathrm{~mm}$. The university's IRB approved this research and patients signed an informed consent agreeing to participate in the study. Patients were allocated into five groups, with five patients in each; a block randomization was done to determine which canine, right or left, would have the SLB or CB bonded. Figure 1 depicts the flow diagram of the progress through the phases of a parallel randomized trial of two groups.

Conventional 0.022-in straight-wire brackets (OvationGAC, Bohemia, NY) were bonded to the lower second

Fig. 1 CONSORT flow chart showing patient flow during the trial

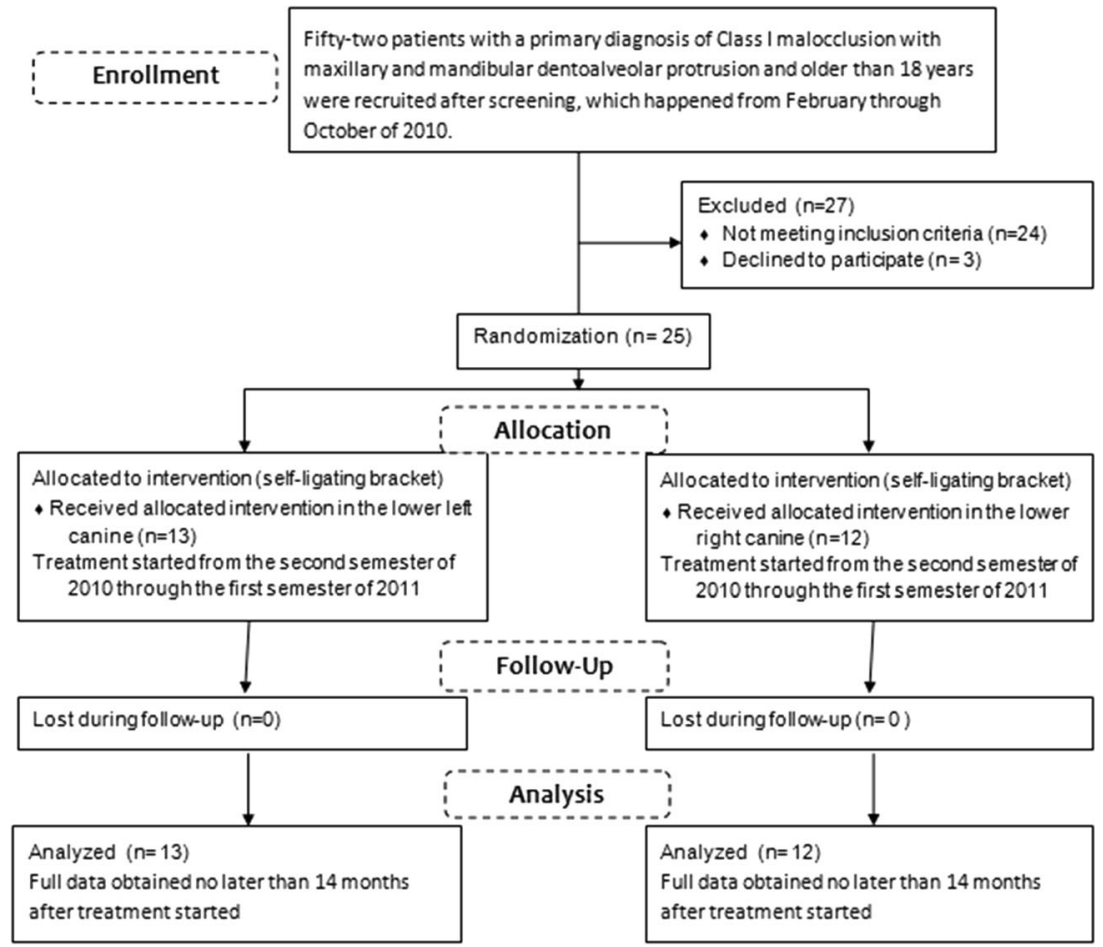


Table 2 Description of cephalometric landmarks and reference points identified on the $45^{\circ}$ lateral tracing

Points and cephalometric Description

landmarks

Point 1

Point 2

Point 3

$\mathrm{MC}$

MA

$\mathrm{CC}$

Anterior reference point

Posterior reference point

Posterior and superior reference point

Mesiobuccal cusp of lower first molar

Mesiobuccal root apex of lower first molar

Cusp of lower canine

CA

Root apex of lower canine

bicuspids and incisors and 0.022 -in tubes were soldered to bands of the first and second molars. Through block randomization, one maxillary canine was bonded with a 0.022 -in SLB (In-Ovation R, GAC), while the other received a 0.022-in CB (Ovation, GAC). Leveling and aligning was conducted conventionally until a 0.020 -in stainless steel (SS) archwire could be passively inserted into the brackets.

A 0.020 -in SS archwire with tight omega loops tied to the first molars was used for the retraction. Second bicuspids and first and second molars were tied together with ligature wire, which were also used to tie the canines' $\mathrm{CB}$ to the archwire. No auxiliary devices such as transpalatal arches, headgear, or elastics were used at anytime. Nickel titanium closed-coil springs (CCS) of $100 \mathrm{~g}$ (GAC, Bohemia, USA) were activated $17 \mathrm{~mm}$ and secured from the hooks of first molars to the hooks of the canine brackets with the help of ligature wires. Every 4 5 weeks, the patients were seen for reactivation of the CCSs to that same distance, which was twice their original length.

Oblique cephalometric radiographs at $45^{\circ}$ were taken from the right and left sides (T1), 7 to 14 days before the extraction and after total canine retraction (T2). The x-ray machine has a

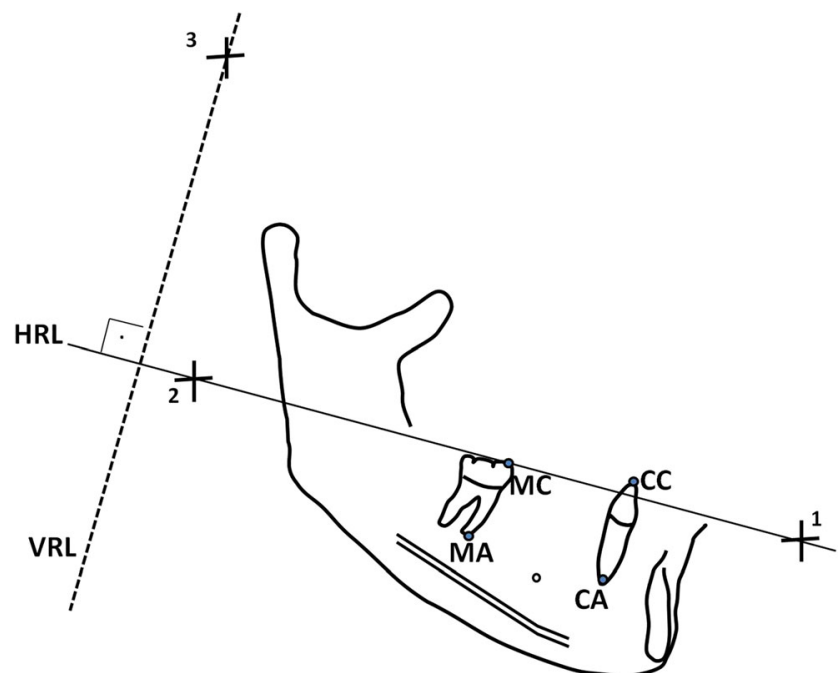

Fig. 2 Tracing with anatomic cephalometric landmarks and reference points as described in Table 2 head support that allows head positioning at $45^{\circ}$ for every radiography. All 25 patients reached the T2 phase without bracket debonds or CCS breakage.

Tracings were hand drawn with a $0.3-\mathrm{mm}$ mechanical pencil on tracing paper by one operator. Two horizontal reference points were marked (Table 2 and Fig. 2) over the functional occlusal plane traced in $\mathrm{T} 1$ in order to determine the horizontal reference line (HRL). Point 1 was located in the anterior region of the tracing and point 2 was in the posterior region of the tracing. A third point was marked above the orbit contour and posterior to the tracing to determine a vertical reference line (VRL), perpendicular to HRL.

Four points were marked on each of the right and left radiographs: MC, MA, CC, and CA (Table 2). All anatomic landmarks and points were digitized on the software DentoFacial Planner Plus (DFP; version 2.0; Toronto, Ontario Canada). T1 and T2 tracings were superimposed using the best fit of mandible bone structures, a method already shown to be valid [23], following the internal symphysis cortical, mandible internal channel, and lower alveolar nerve anterior foramen (Fig. 3) The three reference points were then transferred from $\mathrm{T} 1$ to $\mathrm{T} 2$.

The distances of points $\mathrm{CC}$ and $\mathrm{MC}$ to the LVR, parallel to the initial HRL, were transferred to a Microsoft Excel spreadsheet where $\mathrm{T} 2$ values were subtracted from $\mathrm{T} 1$ values. These calculations allowed the measurement of the total amount of canine retraction at the cusp, and by dividing the total amount of retraction by the number of days for total space closure on each side, the velocity was determined. The amount of AP loss of anchorage of the molar cusps was also calculated similarly. The angle formed by the tooth long axis, determined by the cusp and apex points, and HRL were measured in T1 and T2.

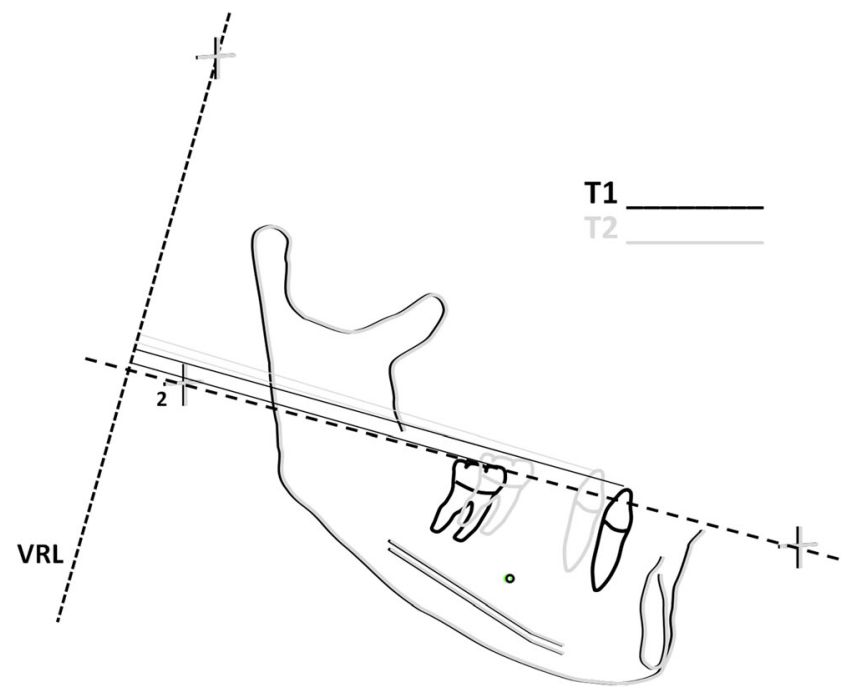

Fig. 3 Partial superimposition of T1 (black line) and T2 (grey). The superimposed stable structures of mandible bone complex, the three reference points, and the lines used to measure the horizontal displacement of the teeth can be seen 
Table 3 Means, standard deviations (SDs) and significance (p) of the comparisons between groups for the variables tested monthly (28 days)

\begin{tabular}{llll}
\hline Variable & SLB group (SD) & CB group (SD) & $P$ value \\
\hline Canine Crown retraction/month (mm) & $0.54(0.13)$ & $0.60(0.20)$ & 0.069 \\
Total canine crown retraction (mm) & $7.16(1.50)$ & $7.51(1.46)$ & 0.187 \\
Total molar crown protraction (mm) & $1.28(0.87)$ & $1.30(0.86)$ & 0.880 \\
Time taken for total space closure (months) & $13.93(3.27)$ & $13.55(3.88)$ & 0.337 \\
Changes on canines long axis (degrees) & $13.71(5.13)$ & $12.88(4.56)$ & 0.410 \\
Changes on molars long axis (degrees) & $-0.56(1.93) \mathrm{ns}$ & $-1.08(2.73) \mathrm{ns}$ & 0.515 \\
\hline
\end{tabular}

Positive degrees indicate distal inclination and negative values indicate mesial inclination

$S L B$ indicates self-ligating brackets, $C B$ conventional brackets, $n s$ non significant values
This allowed an assessment of the changes that occurred on tooth angulations also by subtracting $\mathrm{T} 2$ from $\mathrm{T} 1$.

A single-blinded examiner traced all radiographs, superimposed, and digitized them. Each digitalization was repeated after 30 days for method error analysis, which was done through a paired t test, in order to evaluate systematic error, and additionally through the Dahlberg's formula, to access random error.

No significant differences were found by the paired $t$ test between the first and second digitalization, which confirmed the absence of systematic error, while the Dahlberg's formula showed random errors ranging from 0.04 to $0.43 \mathrm{~mm}$ and from $0.72^{\circ}$ to $1.67^{\circ}$. Averages of both first and second measurements were used for statistical analysis.

Statistics were conducted with the software Statistical Package for Social Sciences (SPSS), version 16.0. Since all variables were normally distributed, according to kurtosis and skewness standard error comparisons, paired t tests were used to detect differences between groups.

\section{Results}

No differences were found between the groups for any of the variables tested (Tables 3 and 4). Canines' crowns were retracted the same with SLB and CB $(7.2$ versus $7.5 \mathrm{~mm}$, respectively), and no difference was observed in terms of rates as well ( 0.5 vs. $0.6 \mathrm{~mm} / \mathrm{month}$, respectively). Molars' crowns were protracted the same anteriorly during the retraction for both brackets $(1.3 \mathrm{~mm})$. There was no difference found for the total retraction of the canines, which took around 13.9 months and 13.6 for the SLB and CB groups, respectively. No differences were found either for canine or molar tipping for both SL and CBs, canines tipped posteriorly $13.7^{\circ}$ and $12.9^{\circ}$, respectively, while the molars did not tip during retraction.

No differences $(p=0.908)$ were found when right and left sides of the patients were compared, irrespective of the bracket used (Table 5). Right-side canines were retracted $0.57 \mathrm{~mm} /$ month while left-side canines were retracted at an equal average; standard deviations were slightly different, with $0.16 \mathrm{~mm} / \mathrm{month}$ for the first and $0.18 \mathrm{~mm} / \mathrm{month}$ for the latter.

\section{Harms}

No harm was observed.

\section{Discussion}

No difference on canine displacement rates was observed between the two types of brackets tested in this study. There is only one report on the literature comparing lower canine displacement rates with SLB and CB (for a period of just 8 weeks), where no differences between brackets were found
Table 4 Mean differences, standard deviations (SDs), standard errors of the mean (SEMs), and $95 \%$ confidence intervals of the difference between SLB and CB

\begin{tabular}{|c|c|c|c|c|c|c|}
\hline \multirow[t]{2}{*}{ Variable } & \multirow[t]{2}{*}{ Mean } & \multirow[t]{2}{*}{ SD } & \multirow[t]{2}{*}{ SEM } & \multicolumn{2}{|c|}{$\begin{array}{l}95 \% \text { confidence } \\
\text { interval of the difference }\end{array}$} & \multirow[t]{2}{*}{$P$ value } \\
\hline & & & & Lower & Upper & \\
\hline Canine Crown retraction/month (mm) & 0.070 & 0.18 & 0.036 & -0.005 & 0.145 & 0.069 \\
\hline Total canine crown retraction $(\mathrm{mm})$ & 0.348 & 1.28 & 0.256 & -0.180 & 0.876 & 0.187 \\
\hline Total molar crown protraction $(\mathrm{mm})$ & -0.026 & 0.85 & 0.170 & -0.377 & 0.325 & 0.880 \\
\hline Time taken for total space closure (months) & 0.380 & 1.94 & 0.388 & -0.421 & 1.181 & 0.337 \\
\hline Changes on canines long axis (degrees) & -0.828 & 4.93 & 0.986 & -2.864 & 1.208 & 0.410 \\
\hline Changes on molars long axis (degrees) & 0.514 & 3.88 & 0.777 & -1.091 & 2.119 & 0.515 \\
\hline
\end{tabular}

Positive degrees indicate distal inclination and negative values indicate mesial inclination 
Table 5 Intraindividual differences of the averages of monthly retraction of right and left side canines, irrespective of brackets used for retraction, standard deviation (SD), standard errors of the mean (SEMs), and $95 \%$ confidence intervals

\begin{tabular}{|c|c|c|c|c|c|c|}
\hline \multirow[t]{2}{*}{ Variable } & \multirow[t]{2}{*}{$\begin{array}{l}\text { Mean } \\
\text { differences }\end{array}$} & \multirow[t]{2}{*}{$\mathrm{SD}$} & \multirow[t]{2}{*}{ SEM } & \multicolumn{2}{|c|}{$\begin{array}{l}95 \% \text { confidence } \\
\text { interval of the } \\
\text { difference }\end{array}$} & \multirow[t]{2}{*}{$P$ value } \\
\hline & & & & Lower & Upper & \\
\hline $\begin{array}{l}\text { Canine crown } \\
\text { retraction/ } \\
\text { month } \\
(\mathrm{mm})\end{array}$ & 0.004 & 0.18 & 0.036 & 0.07 & 0.08 & 0.908 \\
\hline
\end{tabular}

similarly to our results [14]. The rates found by us, however, were lower than the ones found by the aforementioned report, which can be explained by the mean age of our sample, which was 10 years higher and could produce slower movements [24], and by differences in forces, since we applied $50 \%$ of the force they used, which could have made movements slower [25]. Moreover, our period of control was much higher, which could have resulted into slower overall rates, since it is known that teeth might move slower toward the end of a long retraction due to increased friction caused by elastic binding between wire and brackets.

The dental arches were aligned and leveled before first bicuspids were extracted. This avoided possible interferences related to canine position in the original malocclusion during its sliding retraction [26]. To this date, this is the first study designed to evaluate displacement rates of lower canines during total retraction, comparing CB and SLB. It has been demonstrated that using sliding mechanics, initial displacement of teeth occurs due to changes in tipping of the tooth involved, until there is no more clearance between the wire and the bracket slot and binding starts to occur. Because of binding, short periods of assessment may not detect the brackets' real influence on teeth displacement rates [27, 28]. The tooth displacement rate may be modified over treatment time due to the extension of hyalinized areas generated [29-31] and to the resistance offered by periodontal tissues that can vary during tooth displacement [32]. Few clinical trials in human samples assessing lower canine retraction are found in literature. Studies focused on demonstrating anchorage loss and the effective rate of retraction are especially difficult to find (Table 6). The studies found report a great variability on lower canine displacement rates. The rates ranged from $0.2 \mathrm{~mm} /$ month [33] to $1.9 \mathrm{~mm} /$ month [31]. Although different biological and biomechanical factors can be related to this variability, the sample size can also influence on the results [31,34]. The variability can be seen from patient to patient and even in the same patient, when sides are compared (Fig. 4).

At the end of retraction, canines showed around $13^{\circ}$ of tipping for both groups. This confirms that canines for both groups were moved in the same manner. This information is very important since different tipping magnitudes between groups might have caused differences in retraction rates, which could not be explained only by the brackets used.

The results of this study demonstrated that bracket type does not influence the rate of tooth movement, but individual variation might. If the patients tested were divided into two groups based on the movement rate, for comparison of the fast (above average) and slow (below average) "movers," a significant difference of $0.26 \mathrm{~mm} / \mathrm{month}$ in the rate of canine retraction would be observed (Table 7). This difference is much higher than the insignificant difference found when brackets were compared or, assuming that a type II error

Table 6 Data of lower canine displacement rates on studies using human sample

\begin{tabular}{|c|c|c|c|c|c|}
\hline Author & Displacement rate (mm/month) & Sample size age (years) & Method of study & Technique & Force applied \\
\hline Storey [33] & 0.21 & $\begin{array}{l}5 \\
12-15 \text { years }\end{array}$ & Casts & With friction & $175-600 \mathrm{~g}$ \\
\hline Hixon [34] & 0.85 & $\begin{array}{l}8 \\
-\end{array}$ & Cephalogram at $25^{\circ}$ & With friction & Higher than $300 \mathrm{~g}$ \\
\hline Boester [29] & 0.98 & $\begin{array}{l}10 \\
12-16 \text { years }\end{array}$ & Cephalogram at $22.5^{\circ}$ & Without friction & $55-310 \mathrm{~g}$ \\
\hline Dincer [35] & $\begin{array}{l}1.03 \\
0.39\end{array}$ & $\begin{array}{l}8 \\
13.6 \text { years }\end{array}$ & Lateral Cephalogram & Without friction & $150 \mathrm{~g}$ \\
\hline Martins [31] & 1.9 & $\begin{array}{l}10 \\
17.4 \text { years }\end{array}$ & Cephalogram at $45^{\circ}$ & Without friction & T-loop \\
\hline Andreasen [36] & 0.96 & $\begin{array}{l}14 \\
-\end{array}$ & Clinical & With friction & $100-500 \mathrm{~g}$ \\
\hline $\mathrm{Oz}[14]$ & $\begin{array}{l}0.88 \\
0.85\end{array}$ & $\begin{array}{l}13 \\
13.6 \text { years }\end{array}$ & Lateral Cephalogram & With friction & $200 \mathrm{~g}$ \\
\hline Thiruvenkatachari [37] & $\begin{array}{l}0.83 \\
0.76\end{array}$ & $\begin{array}{l}10 \\
19.9 \text { years }\end{array}$ & Lateral Cephalogram & With friction & $100 \mathrm{~g}$ \\
\hline Present study & $\begin{array}{l}0.54 \\
0.60\end{array}$ & $\begin{array}{l}25 \\
23.32 \text { years }\end{array}$ & Cephalogram at $45^{\circ}$ & With friction & $100 \mathrm{~g}$ \\
\hline
\end{tabular}


Fig. 4 Canine retraction rates per month with SLB and CB in each patient of the sample

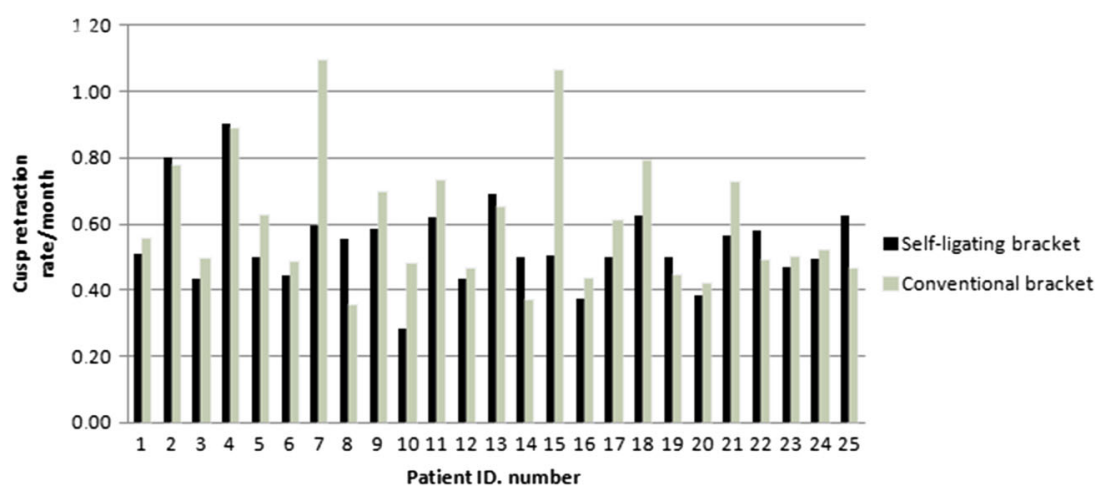

occurred, 4.3 times higher when compared to the difference of $0.06 \mathrm{~mm} / \mathrm{month}$ between SLB and CB. In other words, the rate of canine movement seems to be influenced by individual biological responses of patients, rather than by bracket type [30]. When right and left sides of all are compared (Table 5), no differences were found, independent of the brackets used, further increasing our certainty that the brackets caused no influence on the velocity of retraction.

There was no difference on the anteroposterior anchorage loss for both SLB and CB. The application of lower forces with SLB did not influence the anchorage control. Even though there are three reports [19-21] comparing loss of anchorage of molars when retracting teeth with SLB or CB, no reports have compared the loss of anchorage between SLB and $\mathrm{CB}$ when retracting lower canines. Those three reports, although measuring anchorage loss in different arches, agree with our findings that no difference exists between bracket types.

Molars did not tip; they were moved anteriorly by bodily movement. The fact that there was a large (approximately fivefold) difference between the amount of movement of molars (1.3 mm, for both groups) and canines (7.2 and $7.5 \mathrm{~mm}$, for SLB and CB, respectively) could be explained by different stresses applied to the periodontium, which is known to produce different velocities of movement $[38,39]$. In our study, the canines moved more not only because the molars have a larger root surface area but also because they tipped while the molars did not.

Although blinding of the operator was not feasible at the intervention stage, outcome assessment was blind; therefore, the risks of observation and detection biases can be considered

Table 7 Displacement rates of lower canines by patients divided in two groups based on the "speed of movement"

\begin{tabular}{llll}
\hline & Number & Mean (mm/month) & Diference $(\mathrm{mm} /$ month) \\
\hline Slow movers & 16 & 0.478 & 0.261 \\
Fast movers & 9 & 0.739 & \\
Total & 25 & 0.572 & - \\
\hline
\end{tabular}

low. The main limitation of this study is that retraction of lower canines is only a phase of the orthodontic therapy, which can even be non-existent in most of the cases, and the results cannot be extrapolated to other phases of orthodontic therapy.

Other limitations, such as contacts of the canines during retraction, which could compromise the comparisons, were taken care of by the randomization of sides done to the subjects tested.

Based on the results of this study, conventional or selfligating brackets will exert no influence to the sliding mechanics. On the other hand, it is not possible to predict accurately the time required for tooth retraction in individual patients due to the great amount of variability observed.

\section{Conclusion}

When comparing SLB and CB on lower canine retraction, the following is concluded:

1. Retraction rates were similar

2. Anchorage loss of molars was similar

3. Changes in inclination of lower canines and molars were similar

\section{Compliance with ethical standards}

Conflict of interest The authors declare that they have no conflicts of interest.

Funding The work was supported by the Department of Orthodontics of Universidade Estadual Paulista-Araraquara in São Paulo, the Brazil.

Ethical approval All procedures performed in studies involving human participants were in accordance with the ethical standards of the institutional and/or national research committee and with the 1964 Helsinki Declaration and its later amendments or comparable ethical standards. This research has been approved by Research Etic Committee, FOAr Unesp.

Informed consent Informed consent was obtained from all individual participants included in the study. 


\section{References}

1. Franchi L, Baccetti T, Camporesi M, Barbato E (2008) Forces released during sliding mechanics with passive self-ligating brackets or nonconventional elastomeric ligatures. Am J Orthod Dentofac Orthop 133:87-90

2. Gandini P, Orsi L, Bertoncini C, Massironi S, Franchi L (2008) In vitro frictional forces generated by three different ligation methods. Angle Orthod 78:917-21

3. Hain M, Dhopatkar A, Rock P (2003) The effect of ligation method on friction in sliding mechanics. Am J Orthod Dentofac Orthop 123:416-22

4. Matarese G, Nucera R, Militi A, Mazza M, Portelli M, Festa F, Cordasco G (2008) Evaluation of frictional forces during dental alignment: an experimental model with 3 nonleveled brackets. Am J Orthod Dentofac Orthop 133:708-15

5. Pizzoni L, Ravnholt G, Melsen B (1998) Frictional forces related to self-ligating brackets. Eur J Orthod 20:283-91

6. Reicheneder CA, Gedrange T, Berrisch S, Proff P, Baumert U, Faltermeier A, Muessig D (2008) Conventionally ligated versus self-ligating metal brackets - a comparative study. Eur J Orthod 30:654-60

7. Chen SS, Greenlee GM, Kim JE, Smith CL, Huang GJ (2010) Systematic review of self-ligating brackets. Am J Orthod Dentofac Orthop 137:726 e1-726 e18. doi:10.1016/j.ajodo.2009. 11.009, discussion 726-7

8. Fleming PS, DiBiase AT, Lee RT (2010) Randomized clinical trial of orthodontic treatment efficiency with self-ligating and conventional fixed orthodontic appliances. Am J Orthod Dentofac Orthop 137:738-42

9. Burrow SJ (2010) Canine retraction rate with self-ligating brackets vs conventional edgewise brackets. Angle Orthod 80:438-45

10. Cattaneo PM, Treccani M, Carlsson K, Thorgeirsson T, Myrda A, Cevidanes LH, Melsen B (2011) Transversal maxillary dentoalveolar changes in patients treated with active and passive selfligating brackets: a randomized clinical trial using CBCT-scans and digital models. Orthod Craniofac Res 14:222-33

11. DiBiase AT, Nasr IH, Scott P, Cobourne MT (2011) Duration of treatment and occlusal outcome using Damon3 self-ligated and conventional orthodontic bracket systems in extraction patients: a prospective randomized clinical trial. Am J Orthod Dentofac Orthop 139:e111-e116

12. Mezomo M, de Lima ES, de Menezes LM, Weissheimer A, Allgayer S (2011) Maxillary canine retraction with self-ligating and conventional brackets. Angle Orthod 81:292-7

13. Ong E, McCallum H, Griffin MP, Ho C (2010) Efficiency of selfligating vs conventionally ligated brackets during initial alignment. Am J Orthod Dentofac Orthop 138(138):e1-7, discussion 138-9

14. Oz AA, Arici N, Arici S (2011) The clinical and laboratory effects of bracket type during canine distalization with sliding mechanics. Angle Orthod 82:326-32

15. Pandis N, Polychronopoulou A, Eliades T (2010) Active or passive self-ligating brackets? a randomized controlled trial of comparative efficiency in resolving maxillary anterior crowding in adolescents. Am J Orthod Dentofac Orthop 137(12):e1-6, discussion 12-3

16. Pandis N, Polychronopoulou A, Katsaros C, Eliades T (2011) Comparative assessment of conventional and self-ligating appliances on the effect of mandibular intermolar distance in adolescent nonextraction patients: a single-center randomized controlled trial. Am J Orthod Dentofac Orthop 140:e99-e105

17. Wahab RMA, Idris H, Yacob H, Ariffin SHZ (2011) Comparison of self- and conventional-ligating brackets in the alignment stage. Eur J Orthod 34:176-181

18. Scott P, DiBiase AT, Sherriff M, Cobourne MT (2008) Alignment efficiency of Damon3 self-ligating and conventional orthodontic bracket systems: a randomized clinical trial. Am J Orthod Dentofac Orthop 134(470):e1-8

19. da Costa MA, Junior LG, Martins RP, Vianna AP (2016) Canine retraction and anchorage loss self-ligating versus conventional brackets in a randomized split-mouth study. Angle Orthod 84(5): 846-852. doi:10.2319/100813-743.1

20. de Almeida MR, Herrero F, Fattal A, Davoody AR, Nanda R, Uribe F (2013) A comparative anchorage control study between conventional and self-ligating bracket systems using differential moments. Angle Orthod 83:937-42

21. Machibya FM, Bao X, Zhao L, Hu M (2013) Treatment time, outcome, and anchorage loss comparisons of self-ligating and conventional brackets. Angle Orthod 83:280-5

22. Dupont WD, Plummer WD Jr (1990) Power and sample size calculations. A review and computer program. Control Clin Trials 11:116-28

23. Sakima MT, Sakima CG, Melsen B (2004) The validity of superimposing oblique cephalometric radiographs to assess tooth movement: an implant study. Am J Orthod Dentofac Orthop 126: 344-53

24. Darendeliler MA, Darendeliler H, Uner O (1997) The drum spring (DS) retractor: constant and continuous force for canine retraction. Eur J Orthod 19:115-30

25. Yee JA, Turk T, Elekdag-Turk S, Cheng LL, Darendeliler MA (2009) Rate of tooth movement under heavy and light continuous orthodontic forces. Am J Orthod Dentofac Orthop 136(150):e1-9, discussion $150-1$

26. Nanda R, Kuhlberg A, Uribe F (2005) Biomechanic basis of extraction space closure. In: Nanda R (ed) Book title. Elsevier Saunders, St Louis

27. Burrow SJ (2009) Friction and resistance to sliding in orthodontics: a critical review. Am J Orthod Dentofac Orthop 135:442-7

28. Ehsani S, Mandich MA, El-Bialy TH, Flores-Mir C (2009) Frictional resistance in self-ligating orthodontic brackets and conventionally ligated brackets. A systematic review. Angle Orthod 79:592-601

29. Boester CH, Johnston LE (1974) A clinical investigation of the concepts of differential and optimal force in canine retraction. Angle Orthod 44:113-9

30. Iwasaki LR, Haack JE, Nickel JC, Morton J (2000) Human tooth movement in response to continuous stress of low magnitude. Am J Orthod Dentofac Orthop 117:175-83

31. Martins RP, Buschang PH, Gandini LG Jr, Rossouw PE (2009) Changes over time in canine retraction: an implant study. Am J Orthod Dentofac Orthop 136:87-93. doi:10.1016/j.ajodo.2007.10.044

32. Kurashima K (1963) The viscoelastic properties of the periodontal membrane and alveolar bone. J Stomatol Soc 30:361-85

33. Storey E, Smith R (1952) Force in orthodontics and its relation to tooth movement. Aust J Dent 56:11-8

34. Hixon EH, Atikian H, Callow GE, McDonald HW, Tacy RJ (1969) Optimal force, differential force, and anchorage. Am J Orthod 55: 437-57

35. Dincer M, Iscan HN (1994) The effects of different sectional arches in canine retraction. Eur J Orthod 16(4):317-323

36. Andreasen GF, Zwanziger D (1980) A clinical evaluation of the differential force concept as applied to the edgewise bracket. Am J Orthod 78(1):25-40

37. Thiruvenkatachari B, Ammayappan P, Kandaswamy R (2008) Comparison of rate of canine retraction with conventional molar anchorage and titanium implant anchorage. Am J Orthod Dentofac Orthop 134(1):30-35

38. Hart A, Taft L, Greenberg SN (1992) The effectiveness of differential moments in establishing and maintaining anchorage. Am J Orthod Dentofac Orthop 102:434-42

39. Rajcich MM, Sadowsky C (1997) Efficacy of intraarch mechanics using differential moments for achieving anchorage control in extraction cases. Am J Orthod Dentofac Orthop 112:441-8 